\title{
NULIDAD PARCIAL DEL PGOU 97. IMPLICACIONES DE LAS SENTENCIAS DEL TRIBUNAL SUPERIOR DE JUSTICIA Y DEL TRIBUNAL SUPREMO PARA LA CIUDAD DE MADRID
}

\author{
Rafael Córdoba Hernández (Arquitecto - Profesor asociado DUyOT)
}

Si hay algo que, año tras año, no deja de sorprenderme es ver la cara de sorpresa que pone un alumno de planeamiento cuando se le explica que esa herramienta con la que llevan trabajando prácticamente todo el curso, que lleva un largo proceso de control, tanto ambiental como técnico y jurídico por parte de las distintas administraciones y que condiciona, de una u otra manera, el desarrollo y sostenibilidad del municipio estudiado, puede ser declarada nula. Y es que todavía hay inocencia en la futura profesión.

Y digo inocencia, porque todavía no han llegado a ese punto donde, como técnico, te ves presionado a buscar dobles (o triples) interpretaciones sobre una condición de una ordenanza, intentan que soslayes una evaluación ambiental, que te saltes a la torera una catalogación o que construyas más alturas de las que te permite la normativa, por encargo o demanda de terceros. Todavía confían que la ley tenga una única lectura.

Si ya de por si les resulta sorprenderte la anterior afirmación, cuando te piden un ejemplo y les comentas, desde la Escuela Técnica Superior de Arquitectura de Madrid, que la mayoría de ellos habitan sobre un ejemplo en sí mismo, las caras pasan de sorpresa a susto. $Y$ es que parece mentira que, no ya los estudiantes de urbanismo, sino los ciudadanos de esta gran urbe, desconozcan en su mayoría que teníamos (o tenemos) el planeamiento de nuestro municipio anulado en gran parte por varias sentencias judiciales.

El Plan General de Ordenación Urbana de Madrid (PGOUM 97) en breve cumplirá su mayoría de edad y hasta las elecciones pasadas de mayo de 2015 estaba en revisión con la intención de desembocar en un nuevo modelo, mucho más flexible, para la ciudad. Pero en esta ocasión no entraremos en la discusión de la flexibilidad de ese nuevo modelo y las desastrosas consecuencias que podría tener. Tan sólo nos disponemos a aclarar las cuestiones por las que fue anulado parcialmente para evitar caer en esos errores nuevamente.

En 1991, con la transformación del contexto socioeconómico y el cambio de orientación política del ayuntamiento, el PGOUM 85 sería desacreditado por limitar el crecimiento de la ciudad y con ello dificultar el acceso a la vivienda, por los problemas de movilidad y accesibilidad provocados por el aumento de actividad económica, por el deterioro del Casco Histórico, por la existencia de áreas industriales en ubicaciones centrales y por la pérdida de calidad urbana y ambiental de la capital.

Con la idea de subsanar esta serie de premisas nace un nuevo planteamiento bajo el paraguas de PGOUM 97. El Plan, entre otras actuaciones y propuestas planteaba una serie de desarrollos inmobiliarios que en su mayoría fueron los causantes de esa nulidad parcial que llegaría en 2003. Tienen ya nombres propios como los desarrollos del Este (Los Ahijones, Los Cerros o Los Berrocales), la Operación Campamento, la 
ampliación de la ciudad aeroportuaria de Barajas o algunos de los Programas de Actuación Urbanística ${ }^{10}$ (PAUs) diseñados por el equipo redactor. Una nulidad ocasionada porque muchos de estos desarrollos aprobados por la Comunidad de Madrid significaban la transformación de ámbitos de Suelo No Urbanizable de especial protección del planeamiento anterior, en Suelo Urbanizable. Algunas de las actuaciones puestas en entredicho afectaban a suelo protegido por especiales circunstancias en prácticamente la totalidad de su ámbito como eran los casos del Ensanche de San Fernando y Aravaca-La Escorzonera-Montes del Pilar, ambos con el $100 \%$ de su superficie afectada, o El Salobral-Nacional IV y Remate Suroeste Campamento, con más del $98 \%$ protegido.

El mismo año de su entrada en vigencia, se presentó un Recurso ContenciosoAdministrativo ante el Tribunal Superior de Justicia de Madrid impugnando la Aprobación Definitiva. En ella se alegaba la falta de justificación en la desaparición de la especial protección, en su mayoría ecológica, y el cambio de clasificación del suelo afectado. El 27 de febrero de 2003, el Tribunal Superior de Justicia de Madrid dictó Sentencia declarando nulas "aquellas determinaciones que suponían la desclasificación de terrenos clasificados en el Plan General de 1985 como Suelo No Urbanizable de Especial Protección". La falta de motivación que daban lugar a la eliminación de la protección de suelo no urbanizable y su reclasificación en suelo urbanizable quedaban claramente patentes.

La declaración apuntaba que los suelos que gozaban de alguna protección no se podían alterar mediante la determinación de nuevos espacios sin una justificación expresa y motivada de la desaparición de aquellos elementos o valores que fueron argumentados para plantear dicha protección. En este sentido, la nulidad afectaba a 28 ámbitos, incluyendo las iniciadas actuaciones de Montecarmelo, Las Tablas o Sanchinarro. Entre estos desarrollos se planteaban 34.300 viviendas en 1.010 Has.

El 3 de julio de 2007, el Tribunal Supremo dicta nueva Sentencia confirmando la del TSJ de Madrid pero excluyendo de la declaración de nulidad a varios Sectores, como el Camino de los Caleros, Montecarmelo, Sanchinarro, Las Tablas o el Cerros de los Gamos, dado que su clasificación como urbanizable procedía de modificaciones del PGOU 85 anteriores al objeto del Recurso Contencioso-Administrativo interpuesto.

Durante el año siguiente, tanto el Ayuntamiento como la Comunidad de Madrid elaborarán una Memoria justificativa intentando subsanar las deficiencias producidas en la reclasificación a efectos de regularizar la situación y dar de nuevo cobertura a la ordenación afectada por dichas Sentencias.

El acuerdo de 24 de enero de 2008 fue nuevamente impugnada por una doble vía, por una parte, a través del incidente de ejecución de sentencia que desembocó en los autos del TSJM de 10 de enero de 2011 y de 18 de febrero del mismo año recurridos en el recurso de casación no 2092/2011 en el que se ha dictado sentencia de 28 de septiembre de 2012, por la que se anula, entre otros, el acuerdo de Consejo de Gobierno y, por otra parte, por vía de recurso contencioso-administrativo indirecto contra el mismo acuerdo del Consejo de Gobierno de 24 de enero de 2008 que ha

10 Con estos instrumentos se buscaba ordenar y urbanizar completamente, suelos urbanizables que no se encontraban programados en el PGOUM. Con otras palabras, permitía poner en marcha desarrollos que no formaban parte del planeamiento aprobado y que estaban destinados a convertirse en complementarios del mismo. 
concluido con la sentencia dictada en el recurso de casación 1009/2011, de la misma fecha, igualmente anulatoria, entre otros, del acuerdo de 24 de enero de 2008.

El fundamento de ambas sentencias es la imposibilidad legal de la convalidación a posteriori de disposiciones declaradas nulas, carácter reconocido a los planes de ordenación. Así, el Tribunal Supremo dicta dos Sentencias en las que declara la nulidad del PGOU97 en los 22 ámbitos restantes, al entender que no cabe la subsanación de Instrumentos Urbanísticos declarados nulos y, por lo tanto no puede admitir la Memoria justificativa presentada 2008. Los ámbitos finalmente anulados serían los siguientes: UNP 4-04 Ensanche de Coslada, UZP 2-03 Los Ahijones, UNP 405 Ensanche de San Fernando, UZP 2-02 Los Cerros, UZP 2-04 Los Berrocales, UZP 3-01 Valdecarros, UZP 1.04 Vallecas-La Atalayuela, APR 17-01 El Salobral-Nacional IV, APE 09/03 Portillo de El Pardo, APE 09/20 Manzanares Norte, APE 08/06 Colonia Mingorrubio, UNP 4-08 Aravaca-La Escorzonera-Montes del Pilar, Equipamiento General de Valdegrulla, APR 19/04 La Dehesa, UZI 00-06 Arroyo del Fresno, UNP 407 Remate Suroeste Campamento, APE 10-08 Colonia Militar de Cuatro Vientos, APR 10-02 Instalaciones Militares Campamento, UNP 4-01 Ciudad Aeroportuaria-Parque de Valdebebas, UNP 4-10 Solana de Valdebebas, AOE 00-22 Sistema Aeroportuario de Barajas y UNP 4-11 Fuente Fría Norte.

Estas sentencias además planteaban efectos anulatorios "ex tunc", es decir, que los mismos se producen, no a partir de los fallos judiciales, sino que se retrotraen al momento mismo en que en que se aprobó el Plan General. Con ello quedaban afectadas 8.919 hectáreas del municipio, de las cuales 3.334 pasaban a ser nuevamente suelo rústico y el resto, se verían afectadas en cuanto a su ordenación y su desarrollo lógicamente.

La publicación de las Sentencias provocó una gran incertidumbre entre ciudadanos e inversores en su momento. Esta provenía sobre la situación final en la que quedaban esos suelos y el papel que iba a jugar ahora el Ayuntamiento. Muchos de estos desarrollos eran ámbitos en los que todos sus instrumentos urbanísticos tramitados en desarrollo del PGOU 97 habían sido aprobados (planes parciales, proyectos de urbanización y reparcelación) y que, gran parte de ellos tenían juntas de compensación constituidas y en funcionamiento, habiéndose ejecutado obras de urbanización, y otorgado licencias de construcción y de primera ocupación sobre terrenos que, al estar ahora regulados por el anterior planeamiento, pasaban a ser considerados Suelo No Urbanizable de Especial Protección. Sobre estos suelos, como es lógico y normal, no estaba permitida ni la construcción ni la urbanización prevista y/o desarrollada.

Ante este problema sólo cabe una solución y esta debería encauzarse por las Administraciones competentes, Comunidad y Ayuntamiento de Madrid, por un procedimiento de modificación de la clasificación y ordenación de los suelos en cuestión, con la dificultad añadida de tener que ajustarse a la Ley del Suelo vigente de la Comunidad Autónoma de Madrid. Entre tanto, quedan afectadas las actuaciones urbanísticas dado que la nulidad de las determinaciones afectadas del PGOU se extiende a los planes de desarrollo, especialmente, y actos de ejecución con las excepciones y matizaciones que procedan en cada caso.

Estas sentencias llegaban en un momento en el que el equipo de gobierno municipal había decidido revisar el planeamiento, y por lo tanto podía haber optado 
por tener en cuenta la sentencia y revisar o justificar las clasificaciones propuestas. Lejos de adoptar esta sentencia en el nuevo planteamiento del modelo territorial municipal, el consistorio determinó que no podía permitirse esperar a este proceso de Revisión para dar una solución al urbanismo de la ciudad por sus consecuencias económicas y sociales.

La solución planteada fue tramitar una Revisión Parcial de las determinaciones del PGOU 85 aún vigentes, a causa de las sentencias, culminando su proceso y devolviendo el marco jurídico y urbanístico completo al PGOU 97. Esta modificación del planeamiento, conocida popularmente como "Revisión Express" por su rápida concepción, tramitación y aprobación, en menos de unos meses, alcanzó acuerdo del Consejo de Gobierno de la Comunidad de Madrid de 2 de Agosto de 2013.

Una vez aprobada esta modificación, los ámbitos anulados pasaban de nuevo a ser clasificados como urbanos, urbanizables y no urbanizables, conforme a las características ambientales de ese momento y se reanudaba la actividad inmobiliaria en los mismos.

Este último movimiento a la desesperada del Ayuntamiento de Madrid por intentar salvar no sólo el discurso de los últimos años al respecto de su buena gestión del asunto sino el encarecimiento del proceso a causa de los juicios y la no paralización de las obras ha vuelto a ser recurrido por entender que ni acata ni ejecuta correctamente las sentencias de 2012.

Independientemente de este recurso, la situación no ha mejorado excesivamente ni para los vecinos de estos nuevos barrios ni para los inversores. Así, y debido a las sentencias se están resolviendo los recursos planteados, en relación a proyectos de urbanización y reparcelaciones aprobadas, siendo todos los fallos judiciales anulatorios de estos instrumentos. También se están recurriendo muchas de las licencias de obras y de primera ocupación concedidas.

En definitiva, a día de hoy muchos de los desarrollos urbanísticos de la ciudad de Madrid continúan parados porque hace casi veinte años las cosas no se hicieron bien ni se sometieron a los adecuados procesos de justificación o argumentación sobre los valores del territorio. En la actualidad contamos con herramientas de evaluación ambiental que deberían evitar que situaciones similares pudieran acontecer, pero no deberíamos olvidarnos que estas evaluaciones deben ser reales y responder a criterios medioambientales y de sostenibilidad que no deben dar réplica sólo a criterios inmobiliarios.

Si se nos podía hacer complicado explicar a los alumnos o ciudadanos que, un planeamiento tras los controles que lo acompañan en su tramitación puede ser anulado, prefiero no imaginarme lo que significaría explicarles que, el PGOU de una de las principales ciudades españolas jamás llegó a estar vigente en su totalidad durante su periodo de vigencia. Eso sí sería realmente difícil de justificar... 